\title{
Quantitative mass transfer analyses of metabasalt in subduction zone-related metamorphism: A machine-learning based approach
}

\author{
SATOSHI MATSUNO, MASAOKI UNO AND ATSUSHI \\ OKAMOTO
}

Tohoku University

Presenting Author: m.s-rakugo@geo.kankyo.tohoku.ac.jp

Regional mass transfer in subduction-related metamorphic rocks records fluid activities in subduction zones and serves as a key to understand fluid-related processes such as seismic activities (e.g., Hacker et al., 2003) and magma generation in island arcs (e.g., Pearce et al., 2005). However, quantitative metamorphic mass transfer analysis is usually limited in outcrop scales (i.e., $1-10 \mathrm{~m}$ ) due to large protolith heterogeneity inherited in regional scales. To understand mass transfer in subduction zones (i.e., regional scales), a new analytical scheme considering protolith heterogeneity is needed.

To evaluate metamorphic mass transfer, we have developed protolith compositional estimation models using machine learning. The models were built by learning protolith basalt compositional dataset (Ocean Island basalt, Mid-ocean ridge basalt, and Island arc basalt), and designed to estimate trace element compositions from limited numbers of input trace element concentrations (i.e., 2-9 elements). Gradient Boosting Decision Tree was used as a machine learning algorithm, and models were evaluated by the Root Mean Squared Error in the $\log$ unit. $\mathrm{Zr}$, Th, Ti, Nb, $\mathrm{La}, \mathrm{Ce}, \mathrm{Nd}, \mathrm{Yb}$, and $\mathrm{Lu}$ are selected as input elements, and $\mathrm{Rb}, \mathrm{Ba}, \mathrm{U}, \mathrm{K}, \mathrm{La}, \mathrm{Ce}, \mathrm{Pb}, \mathrm{Sr}, \mathrm{Nd}, \mathrm{Y}, \mathrm{Yb}, \mathrm{Lu}$, $\mathrm{Zr}$, Th, Ti, and $\mathrm{Nb}$ are selected as output elements. To optimize the ideal numbers and combinations of input elements, models were constructed for each combination of input and output elements. As a result, it is revealed that basalt trace element compositions can be estimated from only 4 elements inputs. Especially $\mathrm{Th}, \mathrm{Nb}, \mathrm{Zr}$, and $\mathrm{Ti}$, most immobile elements in metamorphism (e.g., Ague 2017), were adopted as representative models. The models were applied to seafloor altered basalt with known protolith to ensure model reliability. Using these models, we evaluated mass transfer in Sanbagawa metamorphic belt as a function of metamorphic grades. Maximum depletion of $\mathrm{Ba}$ and $\mathrm{Sr}$ at each grade correlates with metamorphic grades: Ba has been depleted more than $90 \%$ at the maximum, $\mathrm{Sr}$ has been enriched more than $200 \%$ at the maximum, while some samples have been depleted $50 \%$ at the minimum. These results provide unique insights into elemental budgets and fluid activities in subduction zones. 